\title{
Elucidation of $\boldsymbol{N}^{\mathbf{1}}$-methyladenosine as a Potential Surrogate Biomarker for Drug Interaction Studies Involving Renal Organic Cation Transporters ${ }^{\circledR}$
}

\author{
Takeshi Miyake, Tadahaya Mizuno, Issey Takehara, Tatsuki Mochizuki, Miyuki Kimura, \\ Shunji Matsuki, Shin Irie, Nobuaki Watanabe, Yukio Kato, Ichiro leiri, Kazuya Maeda, \\ Osamu Ando, and Hiroyuki Kusuhara
}

Laboratory of Molecular Pharmacokinetics, Graduate School of Pharmaceutical Sciences, the University of Tokyo, Tokyo, Japan (Tak.M., Tad.M., Tat.M., K.M., H.K.); Biomarker Department (I.T.) and Drug Metabolism \& Pharmacokinetics Research Laboratories (N.W., O.A.), Daiichi-Sankyo Co., Ltd., Tokyo, Japan; Fukuoka Mirai Hospital Clinical Research Center, Fukuoka, Japan (M.K., S.M., S.I.); Faculty of Pharmacy, Institute of Medical, Pharmaceutical and Health Sciences, Kanazawa University, Kanazawa, Japan (Y.K.); and Department of Clinical Pharmacokinetics, Graduate School of Pharmaceutical Sciences, Kyushu University, Fukuoka, Japan (I.I.)

Received March 27, 2019; accepted September 7, 2019

\section{ABSTRACT}

Endogenous substrates are emerging biomarkers for drug transporters, which serve as surrogate probes in drug-drug interaction (DDI) studies. In this study, the results of metabolome analysis using wild-type and Oct1/2 double knockout mice suggested that $N^{1}$ methyladenosine $\left(\mathrm{m}^{1} \mathrm{~A}\right)$ was a novel organic cation transporter (OCT) 2 substrate. An in vitro transport study revealed that $m^{1} A$ is a substrate of mouse Oct1, Oct2, Mate1, human OCT1, OCT2, and multidrug and toxin exclusion protein (MATE) 2-K, but not human MATE1. Urinary excretion accounted for $77 \%$ of the systemic elimination of $\mathrm{m}^{1} \mathrm{~A}$ in mice. The renal clearance $(46.9 \pm 4.9 \mathrm{ml} / \mathrm{min}$ per kilogram) of exogenously given $\mathrm{m}^{1} \mathrm{~A}$ was decreased to near the glomerular filtration rates by Oct1/2 double knockout or Mate1 inhibition by pyrimethamine $(16.6 \pm 2.6$ and $24.3 \pm 0.6 \mathrm{ml} / \mathrm{min}$ per kilogram, respectively), accompanied by significantly higher plasma concentrations. In vivo inhibition of OCT2/MATE2-K by a single dose of 7-[(3R)-3-(1-aminocyclopropyl)pyrrolidin-1-yl]-1-[(1R,2S)-2fluorocyclopropyl]-8-methoxy-4-oxoquinoline-3-carboxylic acid in cynomolgus monkeys resulted in the elevation of the area under the curve of $\mathrm{m}^{1} \mathrm{~A}$ (1.72-fold) as well as metformin (2.18-fold). The plasma $\mathrm{m}^{1} \mathrm{~A}$ concentration profile showed low diurnal and interindividual variation in healthy volunteers. The renal clearance

of $\mathrm{m}^{1} \mathrm{~A}$ in younger (21-45 year old) and older (65-79 year old) volunteers ( $244 \pm 58$ and $169 \pm 22 \mathrm{ml} / \mathrm{min}$ per kilogram, respectively) was about 2-fold higher than the creatinine clearance. The renal clearances of $\mathrm{m}^{1} \mathrm{~A}$ and creatinine were $31 \%$ and $17 \%$ smaller in older than in younger volunteers. Thus, $\mathrm{m}^{1} \mathrm{~A}$ could be a surrogate probe for the evaluation of DDIs involving OCT2/MATE2-K.

\section{SIGNIFICANCE STATEMENT}

Endogenous substrates can serve as surrogate probes for clinical drug-drug interaction studies involving drug transporters or enzymes. In this study, $\mathrm{m}^{\mathbf{1}} \mathrm{A}$ was found to be a novel substrate of renal cationic drug transporters OCT2 and MATE2-K. $\boldsymbol{N}^{\mathbf{1}}$-methyladenosine was revealed to have some advantages compared to other OCT2/MATE substrates (creatinine and $\boldsymbol{N}^{\mathbf{1}}$-methylnicotinamide). The genetic or chemical impairment of OCT2 or MATE2-K caused a significant increase in the plasma $\mathrm{m}^{1} \mathrm{~A}$ concentration in mice and cynomolgus monkeys due to the high contribution of tubular secretion to the net elimination of $\mathbf{m}^{\mathbf{1}} \mathbf{A}$. The plasma $\mathbf{m}^{\mathbf{1}} \mathbf{A}$ concentration profile showed low diurnal and interindividual variation in healthy volunteers. Thus, $\mathrm{m}^{1} \mathrm{~A}$ could be a better biomarker of variations in OCT2/MATE2-K activity caused by inhibitory drugs.

\section{Introduction}

Drug transporters are one of the key determinants governing drug pharmacokinetics; thus, they provide sites for drug-drug interactions (DDIs) with concomitantly administered drugs. Inhibition of transporters, which facilitate the drug clearance from the systemic circulation, causes

This study was supported in part by Grants-in-Aid for Scientific Research Foundation B from the Japan Society for the Promotion of Science [Grant 17H04100], the Long-Range Research Initiative by the Japan Chemical Industry Association [Grant 13_PT03-01-3], and a Grants-in-Aid for Clinical Pharmacology Research Foundation Award from the Japanese Society of Clinical Pharmacology and Therapeutics.

https://doi.org/10.1124/dmd.119.087262.

S This article has supplemental material available at dmd.aspetjournals.org. an increase in the systemic exposure of substrate drugs and thus could elevate the risk of adverse reactions. To avoid the risk, the regulatory authorities in the United States, European Union, and Japan have strongly recommended conducting separate clinical studies for investigational inhibitors using probe drugs to firmly evaluate the DDI risks in humans according to their guidelines. Recently, some endogenous substrates have emerged to serve as surrogate probes for clinical DDI studies. Using these endogenous substrates does not require exogenous administration of probe drugs, which enables the early assessment of DDI risks and contributes to overcoming the in vitro-in vivo gap in the DDI predictions (Mariappan et al., 2017; Chu et al., 2018; Rodrigues et al., 2018).

Organic cation transporter (OCT) 2 is predominantly expressed on the basolateral side of human renal proximal tubular epithelial cells and is responsible for the renal influx of water-soluble cationic compounds, 
such as metformin, tetraethylammonium (TEA), and cisplatin (Morrissey et al., 2013). In turn, the efflux of those drugs into urine is mediated by multidrug and toxin extrusion proteins (MATEs) expressed on the apical side of the proximal tubules (Otsuka et al., 2005; Masuda et al., 2006). Human MATEs have two isoforms, MATE1 and MATE2-K, and they play a key role in the tubular secretion of cationic drugs in cooperation with OCT2. To date, dolutegravir, crizotinib, and vandetanib can inhibit OCT2 at the clinical dose to increase the systemic exposure of metformin (Reese et al., 2013; Johansson et al., 2014; Arakawa et al., 2017), whereas MATE inhibitors, such as pyrimethamine (PYR), cimetidine, and trimethoprim also reduce renal clearance of metformin (Elsby et al., 2017), and can exacerbate the intracellular accumulation and nephrotoxicity of cisplatin.

We have reported serum creatinine levels and renal clearances of creatinine and $N^{1}$-methylnicotinamide (NMN) to reflect the transport activity of OCT2/MATEs using 7-[(3R)-3-(1-aminocyclopropyl)pyrrolidin1-yl]-1-[(1R,2S)-2-fluorocyclopropyl]-8-methoxy-4-oxoquinoline-3carboxylic acid (DX-619) and PYR as inhibitors (Imamura et al., 2011; Ito et al., 2012). Indeed, single or multiple doses of OCT2/MATE inhibitors were reported to be accompanied by an increased level of serum creatinine or reduction in renal creatinine clearances, although some inhibitors did not achieve significant unbound concentrations to inhibit OCT2 and/or MATEs considering their in vitro half-maximal inhibitory concentration. Nevertheless, creatinine and NMN have some disadvantages when used as potential biomarkers. Tubular secretion accounts for at most $20 \%$ of the renal creatinine clearance (Breyer and Qi, 2010). The plasma concentration of NMN, a metabolite of niacin (or nicotinamide), exhibited a diurnal change and was almost identical between PYR-treated healthy volunteers and the control group, despite extensive inhibition of the urinary excretion (Ito et al., 2012). Recently, it was also reported that trimethylamine- $N$-oxide, a carnitine-derived metabolite, is a substrate of OCT2 (Teft et al., 2017) and MATE1 (Gessner et al., 2018). However, the contribution of tubular secretion to the renal clearance of trimethylamine- $N$-oxide was not clearly observed in humans based on its renal clearance and glomerular filtration rate. Its plasma concentrations also showed extensive diurnal variation, which was presumably caused by food ingestion (Miyake et al., 2017).

To expand our knowledge on the endogenous probes of OCT2/MATEs, we first investigated the novel endogenous substrate of OCT2 by conducting a metabolome analysis using plasma and urine specimens from wild-type (WT) and Oct1/2 double knockout (dKO) mice. After validation of OCT2/MATE-mediated transport of the candidate compound, $N^{1}$-methyladenosine $\left(\mathrm{m}^{1} \mathrm{~A}\right)$, its utility as a surrogate probe in clinical DDI studies was evaluated in both animals and humans.

\section{Materials and Methods}

Materials and Cell Lines. $N^{1}$-methyladenosine was purchased from Carbosynth (Berkshire, UK). [ $\left.{ }^{3} \mathrm{H}\right] 1$-methyl-4-phenylpyridinium $\left(\mathrm{MPP}^{+}\right.$) $(80 \mathrm{Ci} / \mathrm{mmol}$ ) was obtained from PerkinElmer (Waltham, MA). DX-619 was synthesized at Daiichi-Sankyo Co., Ltd. (Tokyo, Japan). Metformin hydrochloride was purchased from Wako Pure Chemical Industries, Ltd. (Osaka, Japan). All other chemicals and reagents were commercially available and of analytical grade.
Human embryonic kidney 293 (HEK293) cells stably expressing mouse OCT (mOct) 1, mOct2, mouse MATE1 (mMate1), human OCT (hOCT) 1, hOCT2, human MATE (hMATE) 1, and hMATE2-K were established and cultured as described previously (Ito et al., 2010).

Animals. Oct1/2 dKO mice (Jonker et al., 2003) were purchased from Taconic Farms (Germantown, NY). FVB/Njcl mice (CLEA Japan, Tokyo, Japan) were employed as Oct1 and Oct2 gene WT controls. The mice were maintained in an air-conditioned room with lighting at 12 hours intervals, fed a standard animal diet, and received water ad libitum. The mice employed in the current study were from 8 to 12 weeks old. The studies using mice were conducted in accordance with the guidelines provided by the Institutional Animal Care Committee (Graduate School of Pharmaceutical Sciences, University of Tokyo).

Three male cynomolgus monkeys at 3 to 4 years of age were supplied by Shin Nippon Biomedical Laboratories, Ltd. (Tokyo, Japan). They were housed in a temperature- and humidity-controlled room set to a 12-hour light/dark cycle and given access ad libitum to water and a standard laboratory diet. The study using monkeys was carried out in accordance with the guidelines of the Animal Care and Use Committee of Daiichi-Sankyo Co., Ltd.

Metabolome Analysis. The serum and urine samples from WT and Oct1/2 dKO mice were measured with the Metabolon analytical system (Metabolon Inc., Durham, NC). To identify structurally named and unknown molecules, Metabolon applied a nontargeted semiquantitative liquid chromatographytandem mass spectrometry (LC-MS/MS) and gas chromatography/mass spectrometry platform. Identification codes, which start with the letter X, were imparted to unnamed and structually unknown metabolites.

In Vitro Transport Study Using cDNA Transfected Cells. Cells were washed and preincubated with Krebs-Henseleit buffer (118 mM NaCl, $23.8 \mathrm{mM}$ $\mathrm{NaHCO}_{3}, 4.8 \mathrm{mM} \mathrm{KCl}, 1.0 \mathrm{mM} \mathrm{KH}_{2} \mathrm{PO}_{4}, 1.2 \mathrm{mM} \mathrm{MgSO}_{4}, 12.5 \mathrm{mM}$ HEPES, $5 \mathrm{mM}$ glucose, and $1.5 \mathrm{mM} \mathrm{CaCl}_{2}$ ) at $37^{\circ} \mathrm{C}$ for 15 minutes. Then, substrates were added to the wells to initiate uptake. The $\mathrm{pH}$ of the buffer solution was adjusted to 7.4 for OCT-expressing cells and 8.0 for MATE-expressing cells. Incubation buffer was removed and ice-cold Krebs-Henseleit buffer was added to halt the uptake at the designated times. For quantification of $\mathrm{m}^{1} \mathrm{~A}$, cells were recovered in $2 \mathrm{mM}$ ammonium acetate ( $\mathrm{pH}$ 5.0) using a cell scraper and disrupted with a Biorupter (UCD-250HSA; Cosmo Bio, Tokyo, Japan). The specimens were then mixed with a 3 -fold volume of methanol for deproteinization and centrifuged for 5 minutes at $20,000 \mathrm{~g}$. The supernatant was diluted with a 4 -fold volume of $2 \mathrm{mM}$ ammonium acetate ( $\mathrm{pH}$ 5.0) and subjected to LC-MS/MS analysis. For quantification of metformin, cells were recovered in $0.1 \%$ formic acid and disrupted as well. A 3-fold volume of acetonitrile was added, and after centrifugation the supernatant was subjected to LC-MS/MS analysis. A Pierce BCA Protein Assay Kit (Thermo Fisher Scientific, Waltham, MA) was employed to determine the protein concentration with bovine serum albumin as the protein standard.

Kinetic Analysis of In Vitro Data. The data gathered from the saturation study were fitted to the following equation assuming the Michaelis-Menten equation:

$$
\mathrm{CL}_{\text {uptake }}=\frac{V_{\max }}{K_{\mathrm{m}}+S}
$$

where $\mathrm{CL}_{\text {uptake }}$ denotes uptake clearance, calculated by subtracting the $\mathrm{CL}_{\text {uptake }}$ in the empty vector-overexpressing cells from that in the transporter-expressing cells; and $V_{\max }, S$, and $K_{\mathrm{m}}$ represent the maximum transport velocity at the saturating substrate concentration, substrate concentration, and the Michaelis constant, respectively.

The inhibition constants of various inhibitors for OCT2 and MATE2-K were calculated using the following equation:

$$
\mathrm{CL}_{\text {uptake }(+ \text { inhibitor })}=\frac{\mathrm{CL}_{\text {uptake(control) }}}{1+I / K_{\mathrm{i}}}
$$


TABLE 1

List of endogenous compounds of interest in the metabolomics analysis performed on WT and Oct1/2 dKO mice

\begin{tabular}{|c|c|c|c|c|}
\hline \multirow{2}{*}{ Identity } & \multirow{2}{*}{ Platform } & \multirow{2}{*}{ Protonated Molecule } & \multicolumn{2}{|c|}{ Fold Change (Oct1/2 dKO/WT) } \\
\hline & & & Plasma & Urine \\
\hline Pipecolate & LC-MS Pos & 130.1 & $1.43 * * *$ & 1.1 \\
\hline Cadaverine & GC-MS & 174 & N/D & $0.43 *$ \\
\hline 3-methylglutarylcarnitine & LC-MS Pos & 290.1 & $2.65 * *$ & 1.9 \\
\hline$S$-methylcysteine & GC-MS & 162.1 & 1.04 & $0.54 *$ \\
\hline Putrescine & GC-MS & 174 & 0.93 & $0.62 * *$ \\
\hline Docosahexaenoate & LC-MS Neg & 327.3 & $1.35 * *$ & N/D \\
\hline Dihomolinolenate & LC-MS Neg & 305.4 & $1.26^{*}$ & N/D \\
\hline Arachidonate & LC-MS Neg & 303.4 & $1.28 *$ & N/D \\
\hline Docosapentaenoate & LC-MS Neg & 329.4 & $2.23 * *$ & $\mathrm{~N} / \mathrm{D}$ \\
\hline Mead acid & LC-MS Neg & 305.4 & $1.51 * *$ & N/D \\
\hline 12,13-DiHOME & LC-MS Neg & 313.4 & $1.69 * *$ & N/D \\
\hline Choline & LC-MS Pos & 104.2 & $1.21 *$ & $\mathrm{~N} / \mathrm{D}$ \\
\hline 1-Docosahexaenoylglycerophosphocholine & LC-MS Pos & 568.4 & $1.14 *$ & N/D \\
\hline 1-Docosahexaenoyl-glycerophosphoethanolamine & LC-MS Neg & 524.3 & $1.31 *$ & N/D \\
\hline$N^{1}$-methyladenosine & LC-MS Pos & 282.1 & $2.78 * *$ & 0.84 \\
\hline 3-Ureidopropionate & LC-MS Pos & 133.1 & $0.55^{*}$ & $0.66^{*}$ \\
\hline Glycolate (hydroxyacetate) & GC-MS & 177 & $1.23 *$ & 1.19 \\
\hline $\mathrm{X}-11478^{\mathrm{a}}$ & LC-MS Neg & 165.2 & $2 * * *$ & N/D \\
\hline$X-11909^{a}$ & LC-MS Neg & 297.3 & $1.86 * *$ & N/D \\
\hline $\mathrm{X}-12257^{\mathrm{a}}$ & LC-MS Neg & 269.1 & $3.13 *$ & 0.77 \\
\hline$X-16570^{\mathrm{a}}$ & LC-MS Neg & 198.2 & $2.95 *$ & 1.29 \\
\hline $\mathrm{X}-16575^{\mathrm{a}}$ & LC-MS Neg & 293.1 & $2.04 * * *$ & $\mathrm{~N} / \mathrm{D}$ \\
\hline$X-16581^{\mathrm{a}}$ & LC-MS Pos & 304.1 & $2.36 * * *$ & $2.77 * *$ \\
\hline $\mathrm{X}-17307^{\mathrm{a}}$ & LC-MS Pos & 162.1 & N/D & $0.48^{* *}$ \\
\hline $\mathrm{X}-18628^{\mathrm{a}}$ & LC-MS Pos & 931.4 & $2.16^{*}$ & $\mathrm{~N} / \mathrm{D}$ \\
\hline$X-20568^{a}$ & LC-MS Pos & 188.1 & N/D & $0.56^{*}$ \\
\hline
\end{tabular}

GC-MS, gas chromatography/mass spectrometry; LC-MS, liquid chromatography/mass spectrometry; Neg, negative; Pos, positive; 12, 13-DiHOME, ( \pm )12,13-dihydroxy-9Z-octadecenoic acid. N/ D, Not detected. ${ }^{*} P<0.05 ; * * P<0.01 ; * * * P<0.001$, Welch's two-sample $t$ test; value in Oct1/2 dKO mice vs. WT mice.

where $\mathrm{CL}_{\text {uptake(+inhibitor) }}$ and $\mathrm{CL}_{\text {uptake(control) }}$ indicate the uptake with or without inhibitors, respectively; and $I$ and $K_{\mathrm{i}}$ denote the inhibitor concentration and inhibition constant, respectively.

To calculate the kinetic parameters, nonlinear least-squares fitting was performed using the MULTI program (Yamaoka et al., 1981) with the damped Gauss-Newton method algorithm.

Transport Study Using Kidney Slices. Slices (300 $\mu \mathrm{m}$ in thickness) of whole kidneys were prepared from WT and Oct $1 / 2 \mathrm{dKO}$ mice, and incubated at $37^{\circ} \mathrm{C}$ for 5 minutes on a 12-well plate with $1 \mathrm{ml}$ of oxygenated buffer for preincubation. To initiate uptake, the slices were incubated at $37^{\circ} \mathrm{C}$ with $1 \mathrm{ml}$ of oxygenated buffer containing $100 \mu \mathrm{M} \mathrm{m}^{1} \mathrm{~A}$ for 10 minutes. Then, the slices were rapidly removed from the incubation buffer, washed twice with ice-cold buffer to halt the uptake, blotted on filter paper, and weighed. The specimens were homogenized and deproteinized, followed by the determination of $\mathrm{m}^{1} \mathrm{~A}$ concentration by LC-MS/MS. The uptake activity of Oct 1 and Oct2 in the mouse kidney slices was checked with $\left[{ }^{3} \mathrm{H}\right] \mathrm{MPP}^{+}$as the positive control. To quantify the radiolabeled compound, slices were dissolved in $1 \mathrm{ml}$ of Soluene-350 (Packard Instruments, Meriden, CT) overnight at $55^{\circ} \mathrm{C}$. The specimens were mixed with a scintillation cocktail (Hionic Fluor; Packard Instruments) and the radioactivity in the specimens was determined with a liquid scintillation counter (LS6000SE; Beckman Coulter, Brea, CA).

In Vivo Study of $\mathbf{m}^{\mathbf{1}} \mathrm{A}$ in WT and Oct1/2 dKO Mice. Under anesthesia with isoflurane, $\mathrm{m}^{1} \mathrm{~A}(100 \mathrm{nmol} / \mathrm{min}$ per kilogram) was infused through the jugular vein. Blood samples were obtained through the jugular vein at the indicated times after the initiation of infusion and immediately centrifuged at $12,000 \mathrm{~g}$ for 5 minutes to collect the plasma fraction. The urethral meatus was fixed with adhesive reagent (Aron Alpha A Sankyo; Daiichi-Sankyo Co., Ltd.) to avoid missing urine during the administration period. In the PYR-treatment study, a bolus dose of PYR [ $20 \mu \mathrm{mol} / \mathrm{kg}$ in a saline/ethanol/Tween 80 mixture (90/5/5)] was administered via the jugular vein 30 minutes before the initiation of infusion, and rhodamine 123 ( $1 \mathrm{nmol} / \mathrm{min}$ per kilogram), a typical substrate of mMate1, was infused together with $\mathrm{m}^{1} \mathrm{~A}$ as the positive control of mMate1 inhibition. At the end of the experiment, a urine sample was obtained via the urinary bladder and the kidneys were removed. All samples were kept at $-20^{\circ} \mathrm{C}$ until the measurement of $\mathrm{m}^{1} \mathrm{~A}$ concentration by LC-MS/MS analysis.
Pharmacokinetic Analysis in the Steady-State Infusion Study. The total body clearance of plasma $\left(\mathrm{CL}_{\text {tot,p }}\right)$ and the renal clearance with respect to the plasma concentration $\left(\mathrm{CL}_{\mathrm{r}, \mathrm{p}}\right)$ were obtained as follows:

$$
\begin{aligned}
\mathrm{CL}_{\text {tot }, \mathrm{p}} & =\frac{\text { Dose }}{\mathrm{AUC}_{\mathrm{p}}} \\
\mathrm{CL}_{\mathrm{r}, \mathrm{p}} & =\frac{X_{\text {urine }}}{\mathrm{AUC}_{\mathrm{p}}}
\end{aligned}
$$

where Dose and $X_{\text {urine }}$ indicate the amount of compounds administered in 2 hours and excreted into urine, respectively; and $\mathrm{AUC}_{\mathrm{p}}$ indicates the area under the curve (AUC) of the time-plasma concentration for compounds from 0 to 120 minutes and determined with the trapezoidal rule. The apparent tissue-to-plasma concentration ratio $\left(K_{\mathrm{p}, \text { tissue }}\right)$ was determined as follows:

$$
K_{\mathrm{p}, \text { tissue }}=\frac{C_{\text {tissue }}}{C_{\mathrm{p}}}
$$

where $C_{\text {tissue }}$ and $C_{\mathrm{p}}$ indicate the tissue and plasma concentrations of compounds at 120 minutes after administration, respectively.

In Vivo Inhibition Study of OCT2 and MATEs Using DX-619. A crossover study design, where the same three monkeys were employed over a couple of studies, was used with a 2-week washout period between each study. Monkeys were kept under overnight fasting conditions and then provided food after blood sampling at 6 hours, in which they received water ad libitum during the periods. DX-619 $(30 \mathrm{mg} / \mathrm{kg})$ in a $0.5 \%(\mathrm{w} / \mathrm{v})$ methylcellulose (in water) suspension was administered through oral gavage at a dose volume of $5 \mathrm{ml} / \mathrm{kg}$. Additionally, 2 hours after administration of DX-619, metformin was administrated orally at $5 \mathrm{mg} / \mathrm{kg}$ (dosing volume: $5 \mathrm{ml} / \mathrm{kg}$ ) in a $0.5 \%(\mathrm{w} / \mathrm{v})$ methylcellulose suspension. Blood samples were obtained through the femoral vein, collected in tubes coated with heparin at -2 (before metformin dosing), $0.25,0.5,1,2,4,6$, and 24 hours after metformin dosing. The specimens were kept on ice before being centrifuged to obtain plasma specimens $\left(15,000 \mathrm{rpm}, 2\right.$ minutes at $\left.4{ }^{\circ} \mathrm{C}\right)$. The AUC of the test compounds was determined with the trapezoidal rule.

Clinical Samples. The study protocol was approved by the Ethics Review Boards of The University of Tokyo, Kyushu University, and Sugioka Memorial 

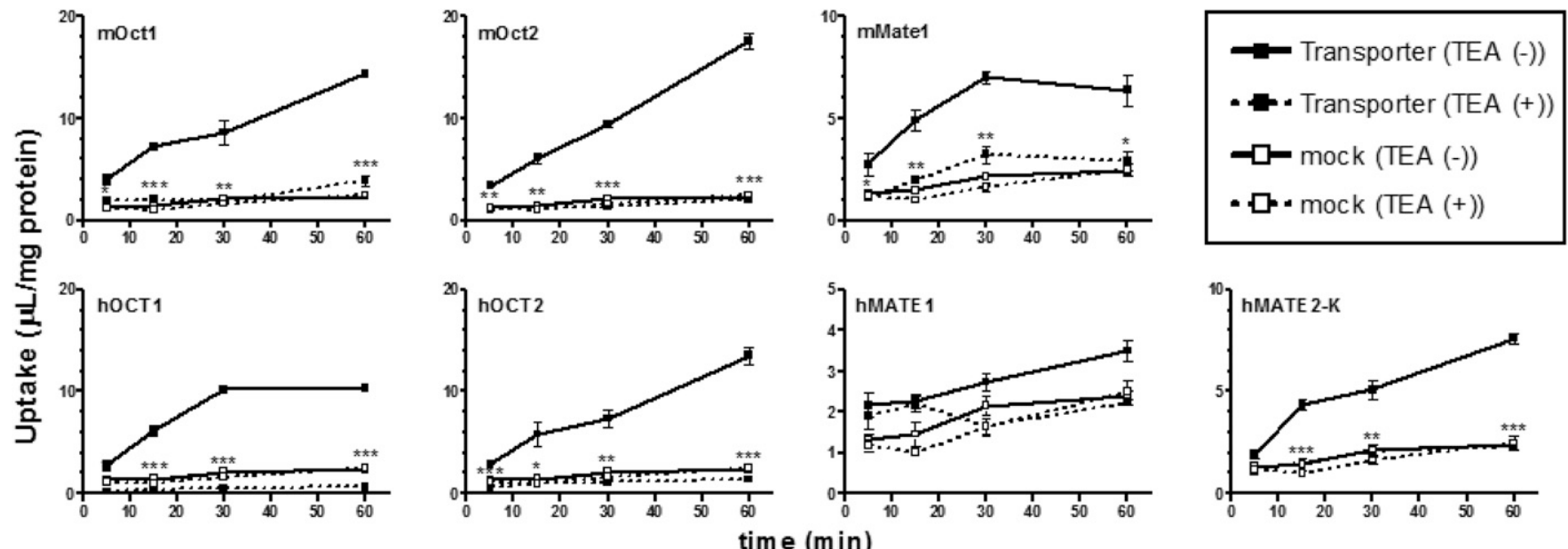

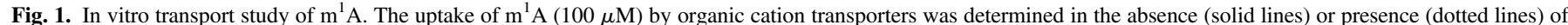

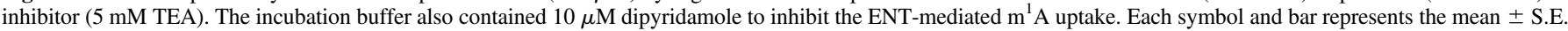
$(n=3)$. $* P<0.05 ; * * P<0.01 ; * * * P<0.001$, the absence vs. presence of $5 \mathrm{mM}$ TEA in transporter-overexpressing cells, Student's two-tailed unpaired $t$ test.

Hospital. Written informed consent was confirmed from all participants prior to their inclusion in this study. The plasma and urine samples were those from our previously performed clinical DDI study (Miyake et al., 2017). Briefly, the study was a single-arm, nonrandomized study where eight younger and seven older male subjects were enrolled. All participants were in healthy condition and not on any medication. They received the following drugs in a cassette after overnight fasting for the investigation of the effect of aging on drug transporter activities and cytochrome pigment enzymes, which was the primary objective of the clinical study: alprazolam $0.2 \mathrm{mg}$, atorvastatin $3 \mathrm{mg}$, chlorzoxazone $10 \mathrm{mg}$, pitavastatin $0.4 \mathrm{mg}$, telmisartan $5 \mathrm{mg}$, and valsartan $10 \mathrm{mg}$. Aliquots of plasma specimens were filtered using the Centrifree Ultrafiltration device (Merck Millipore,
Burlington, MA) to evaluate the plasma protein binding of $\mathrm{m}^{1} \mathrm{~A}$. The participants' information is summarized in Supplemental Table 1.

Pharmacokinetic Analysis in the Human Clinical Study. The area under the plasma concentration-time curve from 0 to 24 hours was determined with the trapezoidal rule. The $\mathrm{CL}_{\mathrm{r}, \mathrm{p}}$ values of $\mathrm{m}^{1} \mathrm{~A}$ and creatinine was determined by dividing the amount excreted into the urine from 0 to 24 hours $\left(X_{\text {urine, } 0-24 \mathrm{~h}}\right)$ by the area under the plasma concentration-time curve from 0 to 24 hours $\left(\mathrm{AUC}_{0-24 \mathrm{~h}}\right)$ value as follows:

$$
\mathrm{CL}_{\mathrm{r}, \mathrm{p}}=\frac{X_{\text {urine }, 0-24 \mathrm{~h}}}{\mathrm{AUC}_{0-24 \mathrm{~h}}}
$$

\section{hOCT2}

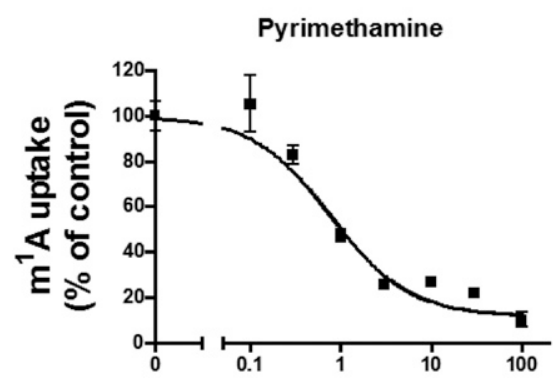

hMATE2-K

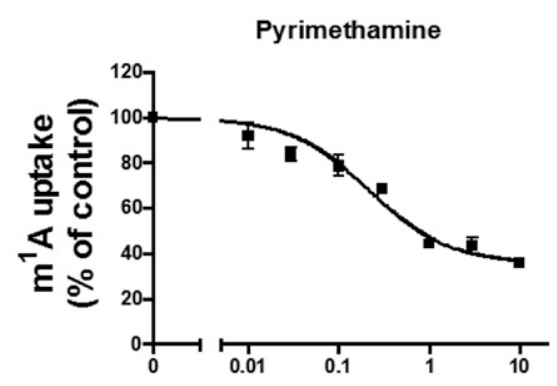

Trimethoprim

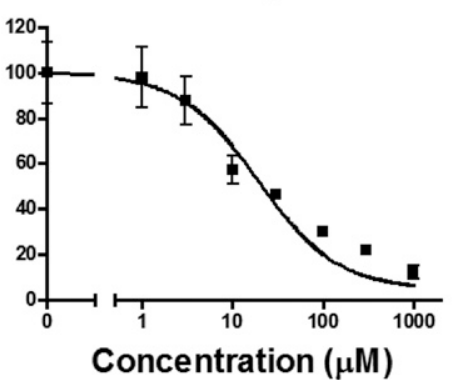

Trimethoprim

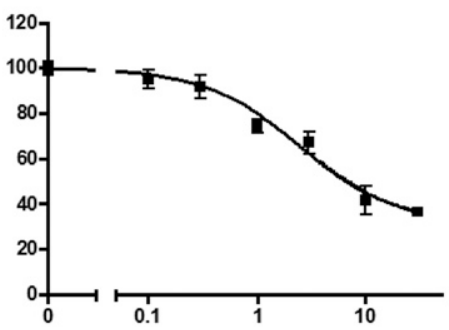

Concentration $(\mu \mathrm{M})$

Fig. 2. Effect of various inhibitors on hOCT2- and hMATE2-K-mediated $\mathrm{m}^{1} \mathrm{~A}$ uptake. The uptake of $\mathrm{m}^{1} \mathrm{~A}(100 \mu \mathrm{M})$ for 60 minutes in HEK293 cells stably expressing hOCT2 or hMATE2-K was determined in the absence and presence of inhibitors (trimethoprim, pyrimethamine, and cimetidine) at the designated concentrations. The transporter-specific uptake of $\mathrm{m}^{1} \mathrm{~A}$ was calculated by subtracting the uptake by empty vector-transfected cells from that by transporter-expressing cells and shown as a proportion to the uptake value in the absence of inhibitors. The solid line represents the fitted line obtained by nonlinear regression analysis as described in Materials and Methods. Each symbol and bar represents the mean \pm S.E. $(n=3)$. 
TABLE 2

Comparison of in vitro inhibition constant of various drugs for OCT2- and MATE2-K-mediated uptake

Each value was determined from the data shown in Fig. 2. The equations for the calculations are described in Materials and Methods. Each value represents the mean \pm computer-calculated S.D.

\begin{tabular}{|c|c|c|c|c|c|c|}
\hline \multirow{2}{*}{ Inhibitor } & \multicolumn{3}{|c|}{ hOCT2 } & \multicolumn{3}{|c|}{ hMATE2-K } \\
\hline & $\mathrm{m}^{1} \mathrm{~A} 100 \mu \mathrm{M}$ & Creatinine $100 \mu \mathrm{M}$ & Metformin $10 \mu \mathrm{M}$ & $\mathrm{m}^{1} \mathrm{~A} 100 \mu \mathrm{M}$ & Creatinine $100 \mu \mathrm{M}$ & Metformin $10 \mu \mathrm{M}$ \\
\hline Trimethoprim & $20 \pm 5$ & $26 \pm 2$ & $20 \pm 2$ & $2.4 \pm 0.4$ & $0.58 \pm 0.11$ & $0.92 \pm 0.04$ \\
\hline Pyrimethamine & $0.64 \pm 0.18$ & $0.93 \pm 0.04$ & $0.61 \pm 0.04$ & $0.22 \pm 0.06$ & $0.35 \pm 0.05$ & $0.22 \pm 0.02$ \\
\hline Cimetidine & $1.8 \pm 0.4$ & $36 \pm 3$ & $59 \pm 1.4$ & $5.3 \pm 1.6$ & $24 \pm 5$ & $5.2 \pm 0.8$ \\
\hline
\end{tabular}

Quantification of Test Compounds in Biologic Specimens by LC-MS/MS. The plasma and urine samples were diluted with 10- and 100-fold volumes of water, respectively. The kidney specimens were homogenized in a 3-fold volume of saline. For quantification of $\mathrm{m}^{1} \mathrm{~A}$, samples were mixed with a 3 -fold volume of methanol and centrifuged at 20,000 $\mathrm{g}$ for 10 minutes. The supernatants were mixed with a 4-fold volume of $2 \mathrm{mM}$ ammonium acetate ( $\mathrm{pH}$ 5.0) and subjected to LC-MS/MS analysis. To quantify rhodamine 123 and creatinine, a 3-fold volume of acetonitrile containing $100 \mathrm{nM}$ creatinine-d3 (internal standard) was added, followed by centrifugation, and then the supernatant was subjected to LC-MS/MS analysis. Samples were analyzed on the QTRAP5500 system (AB SCIEX, Toronto, Canada), equipped with Prominence UFLC (Shimadzu, Kyoto, Japan), in electrospray ionization mode. The measurement conditions are summarized in Supplemental Tables 2 and 3.

Quantification of Metformin and DX-619 in Monkey Plasma by LC-MS/MS. Sample analysis was conducted on the API 4000 system (AB SCIEX), equipped with ACQUITY UPLC (Waters, Milford, MA), in electrospray ionization mode. Each plasma sample was prepared as previously described, followed by mixing with water, acetonitrile, and internal standard solution [niflumic acid $15 \mathrm{ng} / \mathrm{ml}$ in acetonitrile:methanol (75:25)]. After vortexing, the mixtures were filtered by employing MultiScreen Solvinert phobic PTFE $0.45 \mu \mathrm{m}$ (Merck Millipore) and transferred to 96-well plates for LC-MS/MS analysis. The measurement conditions are summarized in Supplemental Table 3.

Statistical Analysis. Data are presented as the mean \pm S.E.M. for the in vitro and in vivo experiments, and the mean \pm S.D. for the clinical study. The statistical analysis was performed with Student's $t$ test, Welch's two-sample $t$ test and Dunnett's post hoc test to detect significant differences between two groups where appropriate $(* P<0.05 ; * * P<0.01 ; * * * P<0.001)$.

\section{Results}

Investigation of Candidate Compounds by Metabolomics Analysis of WT and Oct1/2 dKO Mice. Of the 819 compounds surveyed, the compounds that showed higher plasma concentrations or lower urine concentrations in the knockout mice are summarized in Table 1. Among them, $\mathrm{m}^{1} \mathrm{~A}$ was selected for further analysis because its major elimination pathway in rats was urinary excretion (Dutta and Chheda, 1987) and its serum level was significantly associated with OCT2 single nucleotide polymorphisms (Shin et al., 2014).

Uptake of $\mathbf{m}^{\mathbf{1}} \mathbf{A}$ by Organic Cation Transporters. To verify the $\mathrm{m}^{1} \mathrm{~A}$ transport by OCT2 and other renal cation transporters, an in vitro transport study was performed using transporter-overexpressing HEK293 cells. In the $\mathrm{m}^{1} \mathrm{~A}$ transport studies, $10 \mu \mathrm{M}$ dipyridamole [an inhibitor of equilibrative nucleoside transporters (ENTs)] was added to the incubation buffer to inhibit ENT-mediated $\mathrm{m}^{1} \mathrm{~A}$ uptake in HEK293 cells (Supplemental Fig. 1A). Using $\left[{ }^{3} \mathrm{H}\right] \mathrm{MPP}^{+}$and metformin, it was confirmed that dipyridamole had no effect on OCT- and MATE-mediated uptake (Supplemental Fig. 1B).

The result is summarized in Fig. 1. The $\mathrm{m}^{1} \mathrm{~A}$ uptake in HEK293 cells individually expressing mOct1, mOct 2 , and mMate1 was significantly higher than that in empty-vector transfected cells. Among the human transporters, hOCT1, hOCT2, and hMATE2-K were responsible for the uptake of $\mathrm{m}^{1} \mathrm{~A}$, but hMATE1 was not. The hOCT2-mediated $\mathrm{m}^{1} \mathrm{~A}$ transport was not affected by G808T mutation, a well-known single nucleotide polymorphism of the transporter (Zolk, 2012; Yoon et al., 2013) (Supplemental Fig. 2). The $\mathrm{m}^{1} \mathrm{~A}$ uptake was not saturated at the concentration of $1 \mathrm{mM}$ in all renal cation transporters other than mMate1, in which the $K_{\mathrm{m}}$ and $V_{\max }$ values of $\mathrm{m}^{1} \mathrm{~A}$ were $246 \pm 14 \mu \mathrm{M}$ and $76.7 \pm 3.0 \mathrm{pmol} / \mathrm{min}$ per milligram protein, respectively (Supplemental Fig. 3, A and B). Similarly, $1 \mathrm{mM} \mathrm{m}^{1} \mathrm{~A}$ did not inhibit the metformin uptake by mOct 1, mOct 2 , hOCT2, or hMATE2-K, although $\mathrm{m}^{1} \mathrm{~A}$ concentration-dependent inhibition of metformin uptake by mMate1 was observed with the $K_{\mathrm{i}}$ value of $89.5 \pm 15.1 \mu \mathrm{M}$ (Supplemental Fig. 3C).

The $K_{\mathrm{i}}$ values of trimethoprim, PYR, and cimetidine for hOCT2 and hMATE2-K-mediated $\mathrm{m}^{1} \mathrm{~A}$ uptake were determined (Fig. 2). Concerning substrate dependency, the $K_{\mathrm{i}}$ values of these drugs for $\mathrm{m}^{1} \mathrm{~A}$ uptake were compared with those for creatinine and metformin uptake (Mathialagan et al., 2017) (Table 2). Compared with metformin, the $K_{\mathrm{i}}$ value of cimetidine for hOCT2 was 33 times smaller and that of trimethoprim for hMATE2-K was 2.7-fold greater when $\mathrm{m}^{1} \mathrm{~A}$ was used as the test probe.

$\mathbf{m}^{1}$ A Uptake by Mouse Kidney Slices. Renal cortical slices of WT and Oct $1 / 2 \mathrm{dKO}$ mice were used to elucidate the contribution of OCTs to $\mathrm{m}^{1} \mathrm{~A}$ in the kidney. The effects of Oct $1 / 2 \mathrm{dKO}$ and TEA are shown in Fig. 3. The uptake of $\mathrm{m}^{1} \mathrm{~A}$ into mouse kidney slices was depleted by Oct $1 / 2 \mathrm{dKO}$ or $5 \mathrm{mM}$ TEA, in the same way as $\left[{ }^{3} \mathrm{H}\right] \mathrm{MPP}^{+}$(positive control of the transport activity of OCT). In contrast, it was not affected by $250 \mu \mathrm{M}$ probenecid, a typical organic anion transporter inhibitor.

The Contribution of Oct1/2 to the Kinetics of $\mathbf{m}^{1} \mathrm{~A}$ in Mice. The plasma concentrations of endogenous $\mathrm{m}^{1} \mathrm{~A}$ were measured using LC-MS/MS in WT and Oct1/2 dKO mice, which were $69.0 \pm 6.2$ and $173 \pm 8 \mathrm{nM}$, respectively (mean \pm S.E., $n=3, P<0.001$ ). To confirm
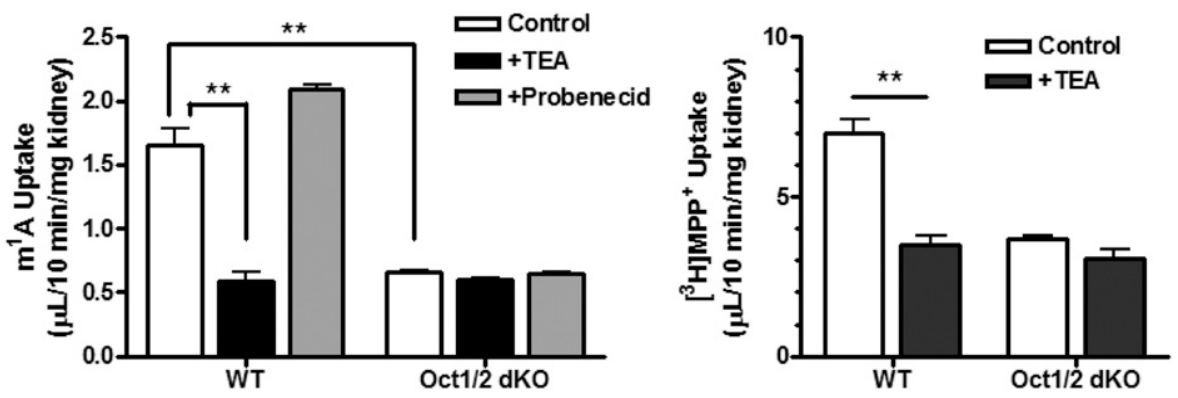

Fig. 3. $\mathrm{m}^{1} \mathrm{~A}$ uptake by renal cortical slices of WT and Oct1/2 dKO mice. The uptake of $\mathrm{m}^{1} \mathrm{~A}(100 \mu \mathrm{M})$ for 10 minutes in renal cortical slices of WT and Oct $1 / 2$ $\mathrm{dKO}$ mice was determined in the absence or presence of $250 \mu \mathrm{M}$ probenecid or $5 \mathrm{mM}$ TEA. Each bar represents the mean \pm S.E. $(n=3) .{ }^{* *} P<0.01$, Dunnett's post hoc test. 

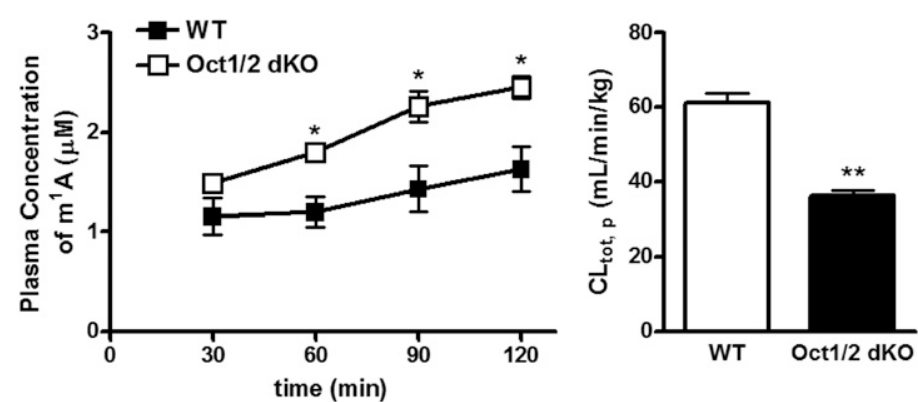

the key role of Oct1/2 in the clearance and tissue distribution of $\mathrm{m}^{1} \mathrm{~A}$ in vivo, an infusion study was carried out with WT and Oct1/2 dKO mice. The dose of $\mathrm{m}^{1} \mathrm{~A}$ ( $100 \mathrm{nmol} / \mathrm{min}$ per milligram) was selected to achieve concentrations higher than the endogenous level, but below its $K_{\mathrm{m}}$ value for mMate1. The kinetic data are shown in Fig. 4 and Table 3. The systemic clearance $\left(\mathrm{CL}_{\mathrm{tot}, \mathrm{p}}\right)$ was mainly explained by the renal clearance $\left(\mathrm{CL}_{\mathrm{r}, \mathrm{p}}\right)$ and decreased significantly by Oct $1 / 2$ depletion, causing about 2 -fold increase of $\mathrm{m}^{1} \mathrm{~A}$ concentration in the plasma. The $\mathrm{CL}_{\mathrm{r}, \mathrm{p}}$ in Oct1/2 $\mathrm{dKO}$ mice was comparable with the glomerular filtration rate (Jonker et al., 2003). Regarding the tissue distribution of $\mathrm{m}^{1} \mathrm{~A}$, the kidney-toplasma ratio $\left(K_{\mathrm{p}, \mathrm{kidney}}\right)$ in Oct $1 / 2 \mathrm{dKO}$ mice exhibited a decreasing tendency compared with that in WT mice. On the other hand, the liver-to-plasma ratio was almost equal between these mice.

The Contribution of Mate1 to the Kinetics of $\mathbf{m}^{\mathbf{1}} \mathbf{A}$ in Mice. We also performed a PYR treatment study using WT mice to check the contribution of Mate 1 to the renal secretion of $\mathrm{m}^{1} \mathrm{~A}$. PYR was administered to mice by a bolus injection 30 minutes prior to the initiation of the $\mathrm{m}^{1} \mathrm{~A}$ infusion, since PYR has a long half-life in the systemic circulation (Ito et al., 2010). The dosage amount of PYR (20 $\mu \mathrm{mol} / \mathrm{kg}$ ) was chosen to inhibit mMate1 strongly, as reported previously (Kito et al., 2019). A reference Mate1 substrate, rhodamine 123 , was simultaneously given to mice with $\mathrm{m}^{1} \mathrm{~A}$. The kinetic change in $\mathrm{m}^{1} \mathrm{~A}$ by the PYR treatment is summarized in Fig. 5 and Table 4. The $\mathrm{CL}_{\mathrm{r}, \mathrm{p}}$ value of $\mathrm{m}^{1} \mathrm{~A}$ was significantly lower in the PYR-treated group, which caused a decrease in $\mathrm{CL}_{\text {tot,p }}$. The PYR treatment also caused an elevation in the $K_{\mathrm{p} \text {,kidney }}$ value of $\mathrm{m}^{1} \mathrm{~A}$, as well as that of rhodamine 123 . The plasma concentration of $\mathrm{m}^{1} \mathrm{~A}$ was about 1.5 -fold higher in the PYR-treated group, while PYR did not affect the plasma concentration of rhodamine 123 .

Effect of DX-619 on the Kinetics of $\mathrm{m}^{1} \mathrm{~A}$ and Metformin in Monkeys. To elucidate the significance of OCT2 and MATE2-K on the

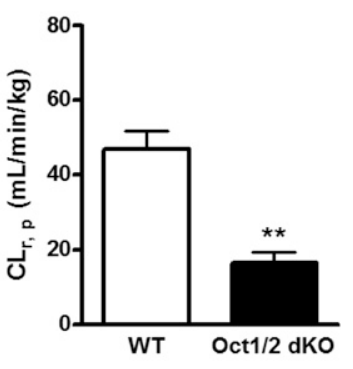

Fig. 4. $\mathrm{m}^{1} \mathrm{~A}$ infusion assay using $\mathrm{WT}$ and Oct $1 / 2 \mathrm{dKO}$ mice. Effect of Oct $1 / 2 \mathrm{dKO}$ on the plasma and concentrations and urinary excretion of exogenously given $\mathrm{m}^{1} \mathrm{~A}(100 \mathrm{nmol} / \mathrm{min}$ per kilogram) in mice. The kinetic parameters were calculated as described in Materials and Methods. Each symbol and bar represents the mean and S.E. $(n=3)$. $* P<0.05 ; * * P<0.01$, Student's two-tailed unpaired $t$ test. $\mathrm{m}^{1} \mathrm{~A}$ kinetics in primates, a single-dose study was carried out with male cynomolgus monkeys administered metformin with or without DX-619, which inhibits those transporters at its therapeutic dose. Prior to this study, $\mathrm{m}^{1} \mathrm{~A}$ transport by cynomolgus monkey OCT2 was confirmed using cDNA-transfected HEK293 cells (Supplemental Fig. 4).

The plasma-concentration profiles of $\mathrm{m}^{1} \mathrm{~A}$, metformin, creatinine, and DX-619 after oral administration of metformin $(5 \mathrm{mg} / \mathrm{kg})$ with and without DX-619 pretreatment $(30 \mathrm{mg} / \mathrm{kg})$ are summarized in Fig. 6. The DX-619 dose (30 mg/kg, by mouth) was designed to achieve sufficient plasma concentrations exceeding by far the reported $K_{\mathrm{i}}$ value $(0.94 \mu \mathrm{M})$ for hOCT2-mediated creatinine uptake (Imamura et al., 2011). The administration of DX-619 resulted in an increase in the $\mathrm{AUC}_{\mathrm{p}}$ of $\mathrm{m}^{1} \mathrm{~A}$ and metformin (Table 5), although not statistically significant ( $P=0.06$ and 0.07 , respectively). The plasma concentration of creatinine exhibited an increasing tendency in the DX-619-treated period.

Determination of the Renal Clearance of $\mathrm{m}^{1} \mathrm{~A}$ and Creatinine in Younger and Older Volunteers. To obtain insight into the dispersion of $\mathrm{m}^{1} \mathrm{~A}$ in humans, $\mathrm{m}^{1} \mathrm{~A}$ and creatinine concentrations in the plasma and urine samples from younger and older healthy volunteers were determined with LC-MS/MS. Binding of $\mathrm{m}^{1} \mathrm{~A}$ to the plasma protein was not detected. As is the case with creatinine, the plasma concentration profile of $\mathrm{m}^{1} \mathrm{~A}$ showed low diurnal and interindividual variation, and no significant difference between the younger and older subjects. The amount of $\mathrm{m}^{1} \mathrm{~A}$ excreted into urine was significantly lower in older subjects (Fig. 7A), leading to a reduction in renal clearance (Table 6). The AUCs of the plasma $\mathrm{m}^{1} \mathrm{~A}$ concentration and creatinine clearance showed a moderately negative correlation (Fig. 7B, left panel). The renal clearance of $\mathrm{m}^{1} \mathrm{~A}$ was about 2-fold higher than the creatinine clearance (Table 6), and the AUCs also showed a moderate correlation (Fig. 7B, right panel).

TABLE 3

Pharmacokinetic parameters of $\mathrm{m}^{1} \mathrm{~A}$ in WT and Oct1/2 dKO mice

The equations to calculate the kinetic parameters are described in Materials and Methods. Each value represents the mean \pm S.E. $(\mathrm{n}=3$ ).

\begin{tabular}{|c|c|c|}
\hline Parameter & WT & Oct $1 / 2 \mathrm{dKO}$ \\
\hline$C_{\mathrm{p}, 120 \min }(\mu \mathrm{M})$ & $1.63 \pm 0.23 *$ & $2.45 \pm 0.11 *$ \\
\hline $\mathrm{AUC}_{\mathrm{p}, 0-120 \min }(\mu \mathrm{mol}$ per $\min / \mathrm{l})$ & $138 \pm 15^{*}$ & $203 \pm 9 *$ \\
\hline$X_{\text {urine }}(\mathrm{nmol})$ & $220 \pm 27 *$ & $103 \pm 13^{*}$ \\
\hline$C_{\text {liver }}(\mu \mathrm{M})$ & $3.31 \pm 0.49 *$ & $5.63 \pm 0.28 *$ \\
\hline$K_{\mathrm{p}, \text { liver }}(\mathrm{ml} / \mathrm{g}$ of liver $)$ & $2.08 \pm 0.36$ & $2.30 \pm 0.09$ \\
\hline$C_{\text {kidney }}(\mu \mathrm{M})$ & $15.6 \pm 6.7$ & $9.27 \pm 0.91$ \\
\hline$K_{\mathrm{p}, \text { kidney }}(\mathrm{ml} / \mathrm{g}$ of kidney $)$ & $8.81 \pm 2.70$ & $3.76 \pm 0.23$ \\
\hline $\mathrm{CL}_{\mathrm{tot}, \mathrm{p}}(\mathrm{ml} / \mathrm{min})$ & $2.10 \pm 0.13 * *$ & $1.11 \pm 0.04 * *$ \\
\hline $\mathrm{CL}_{\mathrm{tot}, \mathrm{p}}(\mathrm{ml} / \mathrm{min}$ per kilogram) & $61.1 \pm 2.7 * *$ & $36.4 \pm 1.3 * *$ \\
\hline $\mathrm{CL}_{\mathrm{r}, \mathrm{p}}(\mathrm{ml} / \mathrm{min})$ & $1.61 \pm 0.16^{* *}$ & $0.511 \pm 0.077 * *$ \\
\hline $\mathrm{CL}_{\mathrm{r}, \mathrm{p}}(\mathrm{ml} / \mathrm{min}$ per kilogram $)$ & $46.9 \pm 4.9 * *$ & $16.6 \pm 2.6^{* *}$ \\
\hline GFR (Jonker et al., 2003) & $0.462 \pm 0.045$ & $0.462 \pm 0.065$ \\
\hline
\end{tabular}

$C_{\text {kidney }}$, kidney concentration; $C_{\mathrm{p}, 120 \mathrm{~min}}$, plasma concentration of compound at 120 minutes after administration; GFR, glomerular filtration rate; $K_{\mathrm{p}, \text { liver }}$, liver-to-plasma ratio; $X_{\text {urine }}$, amount of compound excreted in urine.

${ }^{*} P<0.05 ;{ }^{* *} P<0.01 ;{ }^{* * *} P<0.001$, Student's two-tailed unpaired $t$ test; value in Oct1/2 dKO mice vs. WT mice. 


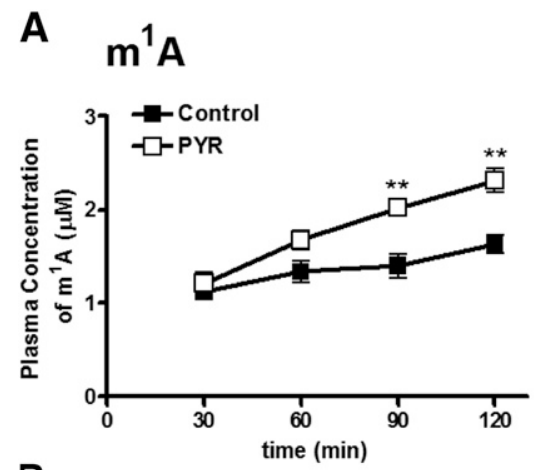

B

Rhodamine 123
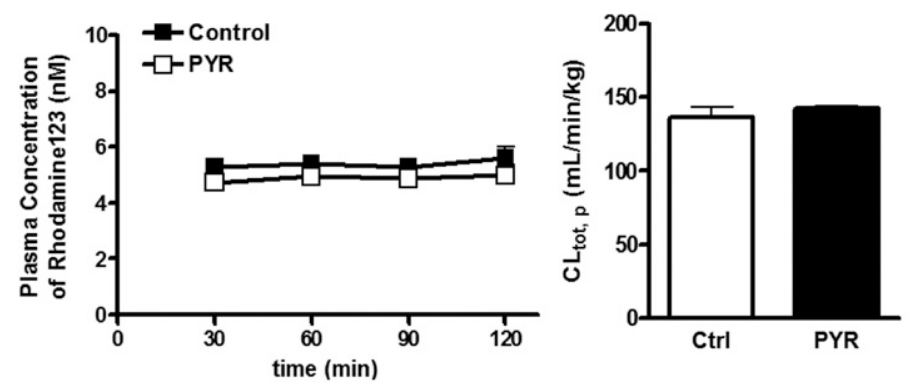

Discussion

Endogenous substrates were recently regarded as surrogate probes for the clinical assessment of DDI risk in drug development. While OCT2 and MATEs are the major drug transporters involved in the proximal tubular secretion of organic cations, sensitive and convenient biomarkers for them have not yet been found. Therefore, the goal of this study was to identify novel endogenous metabolites in plasma that could be used in DDI studies of renal OCT2/MATEs in healthy subjects.

We employed Oct $1 / 2 \mathrm{dKO}$ mice for the metabolomic analysis to search for candidate metabolites because OCT1 is also expressed in the basolateral membrane of proximal tubular epithelial cells along with OCT2 in mice. $\mathrm{m}^{1} \mathrm{~A}$ was suggested to be a potential probe, and was thus subjected to further analysis. It should be noted that $N^{6}$ methyladenosine has the same mass-to-charge transition as $\mathrm{m}^{1} \mathrm{~A}$ in LC-MS/MS analysis. For that reason, we optimized the analytical condition in which analyte peaks of $\mathrm{m}^{1} \mathrm{~A}$ and $N^{6}$-methyladenosine are detected separately (Supplemental Table 1) and could reproduce the

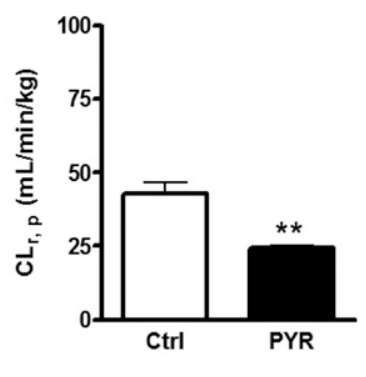

Fig. 5. Effect of PYR on the kinetics of $m^{1} \mathrm{~A}$ in mice. Plasma concentrations and urinary excretion of $\mathrm{m}^{1} \mathrm{~A}$ were determined in control and PYR-treated mice. PYR $(20 \mu \mathrm{mol} / \mathrm{kg})$ was given to mice by bolus injection 30 minutes before starting intravenous infusion of (A) $\mathrm{m}^{1} \mathrm{~A}$ (100 nmol/min per kilogram) and (B) rhodamine 123 (1 nmol/min per kilogram). The kinetic parameters were calculated as described in Materials and Methods. Each symbol and bar represents the mean and S.E. $(n=4)$. $* P<$ 0.05 ; $* * P<0.01$; *** $P<0.001$, Student's two-tailed unpaired $t$ test.

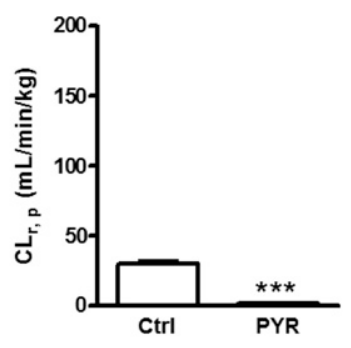

significant alteration of plasma $\mathrm{m}^{1} \mathrm{~A}$ concentration in Oct1/2 $\mathrm{dKO}$ mice. $N^{6}$-methyladenosine concentration was under the lower limit of quantification $(3 \mathrm{nM})$ in any specimen. Plasma concentrations of various kinds of fatty acids were also higher in Oct1/2 dKO mice. However, it was assumed to be the effect of Oct1 knockout, which causes hepatic thiamine deficiency and thereby enhances fatty acid oxidation to compensate for the reduced glycolysis (Chen et al., 2014). $\mathrm{m}^{1} \mathrm{~A}$ is a modified nucleoside that originally presents at position 58 in transfer RNA (tRNA). For the stabilization of the tRNA tertiary structure, the $N^{1}$ position of adenine 58 is methylated to introduce a positive charge into the $\mathrm{T} \psi \mathrm{C}$ loop of tRNA. Under cell stress conditions, tRNA is damaged in order to unfold and then enzymatically cleaved into tRNA-derived stress-induced RNA, followed by degradation to mononucleosides including $\mathrm{m}^{1} \mathrm{~A}$ (Mishima et al., 2014). We considered another possibility for the synthesis of $\mathrm{m}^{1} \mathrm{~A}$, such as direct methylation of adenosine by gut flora, which motivated us to compare the endogenous level of $\mathrm{m}^{1} \mathrm{~A}$ in plasma and various tissues between germ-free

TABLE 4

Pharmacokinetic parameters of $\mathrm{m}^{1} \mathrm{~A}$ and rhodamine 123 in control and PYR-treated mice

The equations to calculate the kinetic parameters are described in Materials and Methods. Each value represents the mean \pm S.E. (n $=4$ ); Student's two-tailed unpaired t test; value in control mice vs. PYR-treated mice.

\begin{tabular}{|c|c|c|c|c|c|c|}
\hline \multirow{2}{*}{ Parameter } & \multicolumn{3}{|c|}{$\mathrm{m}^{1} \mathrm{~A}$} & \multicolumn{3}{|c|}{ Rhodamine 123} \\
\hline & Control & PYR & Unit & Control & PYR & Unit \\
\hline$C_{\mathrm{p}, 120 \min }$ & $1.64 \pm 0.10$ & $2.31 \pm 0.13^{* *}$ & $\mu \mathrm{M}$ & $5.61 \pm 0.46$ & $5.01 \pm 0.39$ & $\mathrm{nM}$ \\
\hline $\mathrm{AUC}_{\mathrm{p}, 0-120 \mathrm{~min}}$ & $140 \pm 9$ & $182 \pm 11^{*}$ & $\mu \mathrm{mol}$ per $\min / 1$ & $564 \pm 27$ & $512 \pm 12$ & nmol per min/l \\
\hline$X_{\text {urine }}$ & $170 \pm 10$ & $126 \pm 5^{* *}$ & nmol & $477 \pm 32$ & $21.2 \pm 3.4^{* * *}$ & pmol \\
\hline$C_{\text {kidney }}$ & $7.22 \pm 1.82$ & $34.0 \pm 5.4 * *$ & $\mu \mathrm{M}$ & $0.800 \pm 0.074$ & $1.86 \pm 0.21$ & $\mu \mathrm{M}$ \\
\hline$K_{\mathrm{p}, \text { kidney }}$ & $4.4 \pm 1.1$ & $14.7 \pm 2.0 * *$ & $\mathrm{ml} / \mathrm{g}$ of kidney & $143 \pm 6$ & $381 \pm 70$ & $\mathrm{ml} / \mathrm{g}$ of kidney \\
\hline $\mathrm{CL}_{\text {tot,p }}$ & $2.32 \pm 0.12$ & $1.78 \pm 0.13^{*}$ & $\mathrm{ml} / \mathrm{min}$ & $3.93 \pm 0.18$ & $4.07 \pm 0.05$ & $\mathrm{ml} / \mathrm{min}$ \\
\hline $\mathrm{CL}_{\text {tot,p }}$ & $80.4 \pm 4.9$ & $61.9 \pm 3.6^{*}$ & $\mathrm{ml} / \mathrm{min}$ per kilogram & $136 \pm 8$ & $142 \pm 2$ & $\mathrm{ml} / \mathrm{min}$ per kilogram \\
\hline $\mathrm{CL}_{\mathrm{r}, \mathrm{p}}$ & $1.23 \pm 0.11$ & $0.698 \pm 0.035^{* *}$ & $\mathrm{ml} / \mathrm{min}$ & $0.851 \pm 0.073$ & $0.0416 \pm 0.0073$ & $\mathrm{ml} / \mathrm{min}$ \\
\hline $\mathrm{CL}_{\mathrm{r}, \mathrm{p}}$ & $42.6 \pm 4.1$ & $24.3 \pm 0.6^{* *}$ & $\mathrm{ml} / \mathrm{min}$ per kilogram & $29.6 \pm 3.1$ & $1.44 \pm 0.21$ & $\mathrm{ml} / \mathrm{min}$ per kilogram \\
\hline GFR (Jonker et al., 2003) & $0.462 \pm 0.045$ & $0.462 \pm 0.065$ & $\mathrm{ml} / \mathrm{min}$ & & & \\
\hline
\end{tabular}

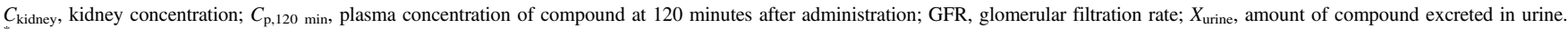
${ }^{*} P<0.05 ; * * P<0.01 ; * * * P<0.001$. 

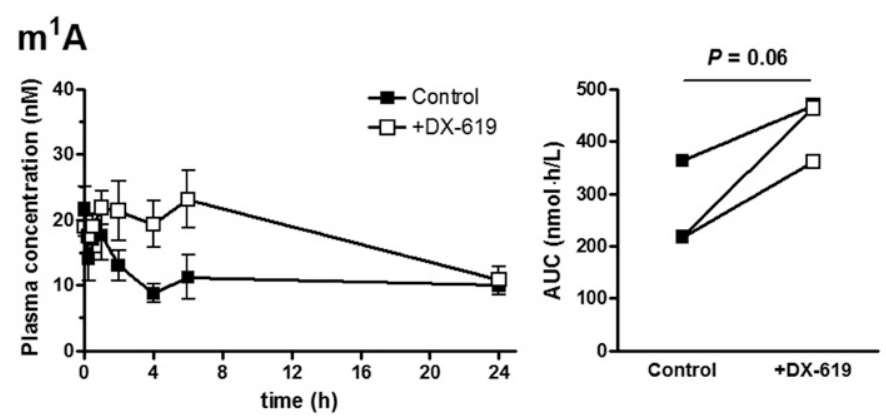

Creatinine
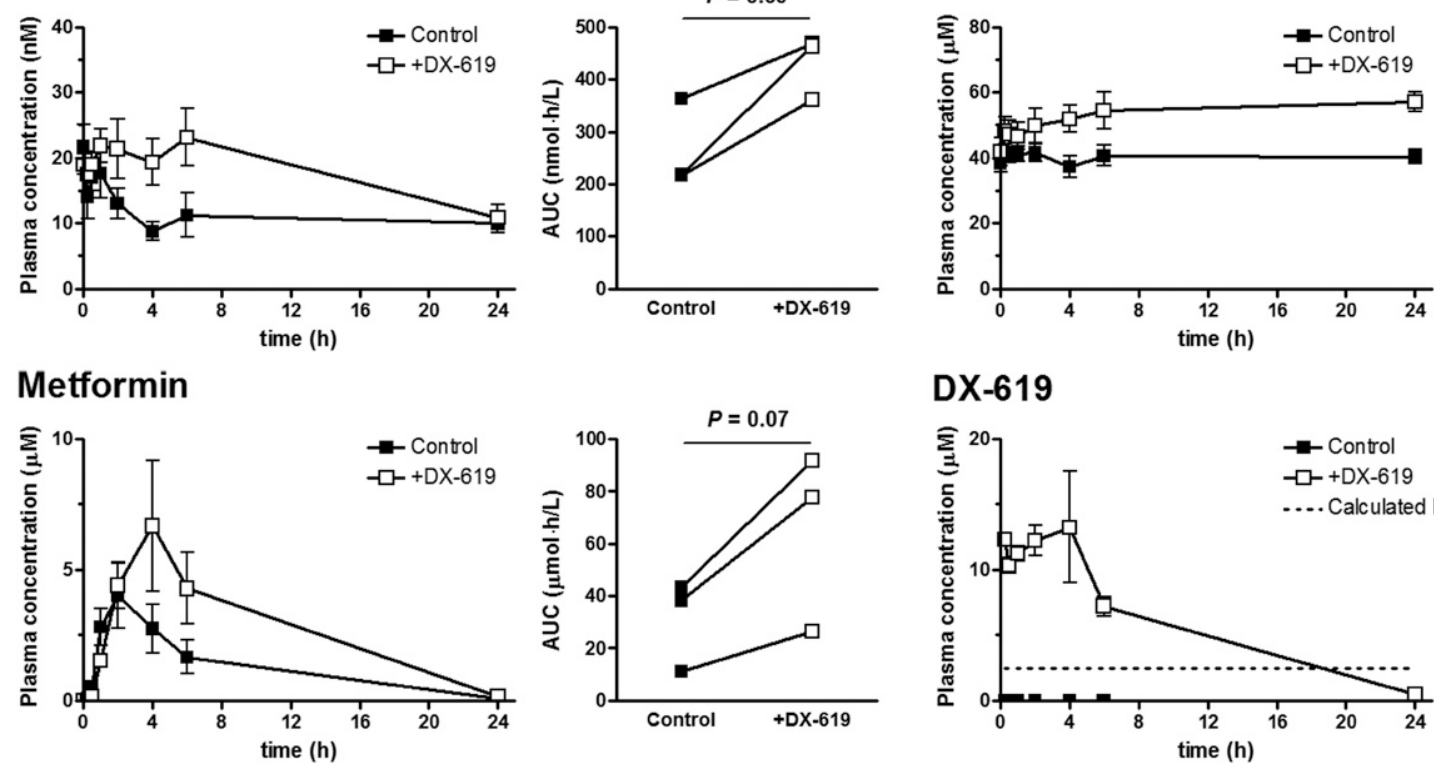

\section{DX-619}

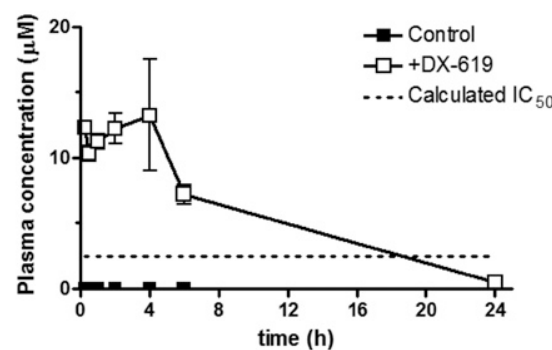

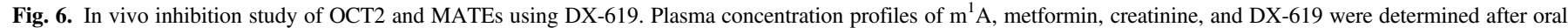

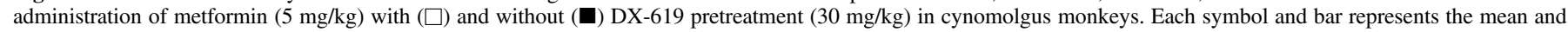
S.E. $(n=3)$. $P$ value was calculated by Student's two-tailed paired $t$ test.

mice and specific-pathogen-free mice (Supplemental Fig. 5). The results showed no significant differences in the plasma, liver, and kidney concentrations, whereas significant differences in the intestine and decreasing tendency in the brain were observed. On the other hand, the abundance of trimethylamine- $N$-oxide, whose precursor trimethylamine is produced by gut flora-mediated metabolism, was diminished in germ-free mice, indicating that the contribution of gut flora to the $\mathrm{m}^{1} \mathrm{~A}$ disposition is negligible. In addition, in all tissues tested, endogenous $\mathrm{m}^{1} \mathrm{~A}$ was detected at about 10 -fold higher concentration than in plasma.

The in vitro transport study revealed that $\mathrm{m}^{1} \mathrm{~A}$ is a substrate of not only mOct 2 and hOCT2, but also mOct 1 , mMate 1 , hOCT1, and hMATE2-K (Fig. 1). Except for mMate1 with a $K_{\mathrm{m}}$ value of $246 \pm$ $14 \mu \mathrm{M}$, renal cation transporter-mediated $\mathrm{m}^{1} \mathrm{~A}$ uptake was not saturated even at the concentration of $1 \mathrm{mM}$ (Supplemental Fig. 3), indicating the low-affinity and high-capacity nature of $\mathrm{m}^{1} \mathrm{~A}$ transport by those transporters. Considering the substrate dependency of the $K_{\mathrm{i}}$ values (Hacker et al., 2015; Lechner et al., 2016; Mathialagan et al., 2017), we compared the $K_{\mathrm{i}}$ values of the three inhibitors for $\mathrm{m}^{1} \mathrm{~A}$ uptake with those for other typical substrates. Trimethoprim and PYR exhibited almost identical inhibition constants for all substrates, whereas the $K_{\mathrm{i}}$ value of cimetidine varied according to each substrate.
Further studies are necessary to dteremine whether this finding is in vivo relevant in future clinical studies.

Next, we investigated the physiologic significance of OCTs in $\mathrm{m}^{1} \mathrm{~A}$ transport with Oct1/2 dKO mice. We have clarified that TEA-sensitive uptake of $\mathrm{m}^{1} \mathrm{~A}$ was completely abolished in the kidney slices from Oct $1 / 2 \mathrm{dKO}$ mice (Fig. 3). The results of the infusion study showed that the systemic clearance of $\mathrm{m}^{1} \mathrm{~A}$ was dominated mostly by urinary excretion. Approximately $80 \%$ of intravenously given $\mathrm{m}^{1} \mathrm{~A}$ was recovered unchanged in the urine in WT mice. The renal clearance of $\mathrm{m}^{1} \mathrm{~A}$ was decreased to the value comparable with the glomerular filtration rate in Oct1/2 dKO mice (Table 3), causing its accumulation in the plasma (Fig. 4). A decreasing tendency of the $K_{\mathrm{p} \text {,kidney }}$ value of $\mathrm{m}^{1} \mathrm{~A}$ was observed in Oct1/2 dKO mice, but there was too large a variation in this parameter in WT mice to obtain statistical significance for unknown reasons. In contrast, the liver-to-plasma ratio was much lower than the $K_{\mathrm{p} \text {,kidney value and almost identical between WT and }}$ Oct1/2 dKO mice, indicating little contribution of mOct1 to the hepatic uptake of $\mathrm{m}^{1} \mathrm{~A}$. The importance of mMate 1 in the urinary excretion of $\mathrm{m}^{1} \mathrm{~A}$ was suggested by the in vivo study using the MATE1 inhibitor PYR. PYR significantly decreased the renal clearance of $\mathrm{m}^{1} \mathrm{~A}$, accompanied by the increased kidney-to-plasma ratio and plasma concentration of $\mathrm{m}^{1} \mathrm{~A}$ (Fig. 5), attributable to a significant reduction in

TABLE 5

The AUCs of metformin and $\mathrm{m}^{1} \mathrm{~A}$ in control and DX-619-treated monkeys

\begin{tabular}{ccccc}
\hline Treatment & 1 & 2 & 3 & Mean \pm S.E. \\
\hline $\mathrm{m}^{1} \mathrm{~A}(\mathrm{nM} \cdot \mathrm{h})$ & & & & \\
Control & 364 & 216 & 219 & $266 \pm 49$ \\
+DX-619 & 468 & 361 & 264 & $431 \pm 35$ \\
Fold change & 1.29 & 1.67 & 2.12 & $1.72 \pm 0.24$ \\
Metformin $(\mu \mathrm{M} \cdot \mathrm{h})$ & & 11.1 & 38.3 & $31.0 \pm 10.0$ \\
Control & 43.5 & 26.5 & 77.6 & $65.3 \pm 19.9$ \\
+DX-619 & 91.9 & 2.39 & 2.03 & $2.18 \pm 0.11$ \\
Fold change & 2.11 & & & \\
\hline
\end{tabular}


A

$\mathrm{m}^{1} \mathrm{~A}$
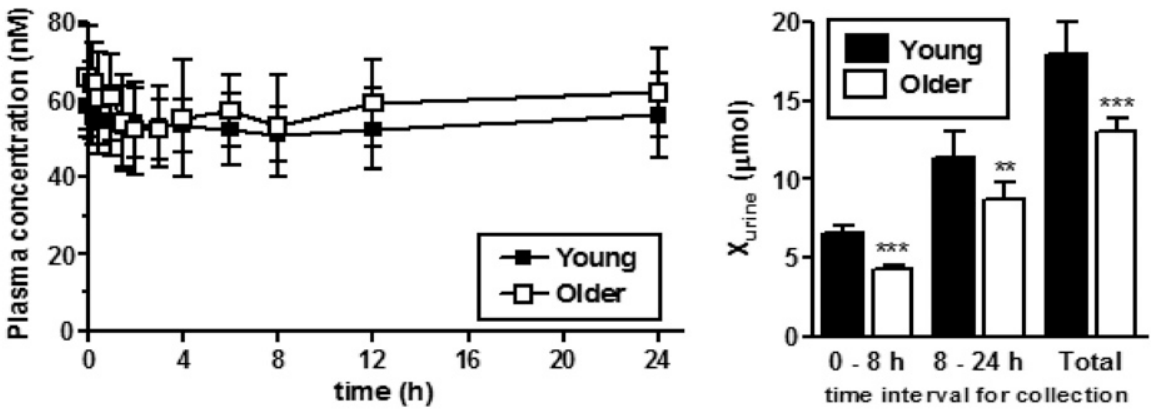

\section{Creatinine}
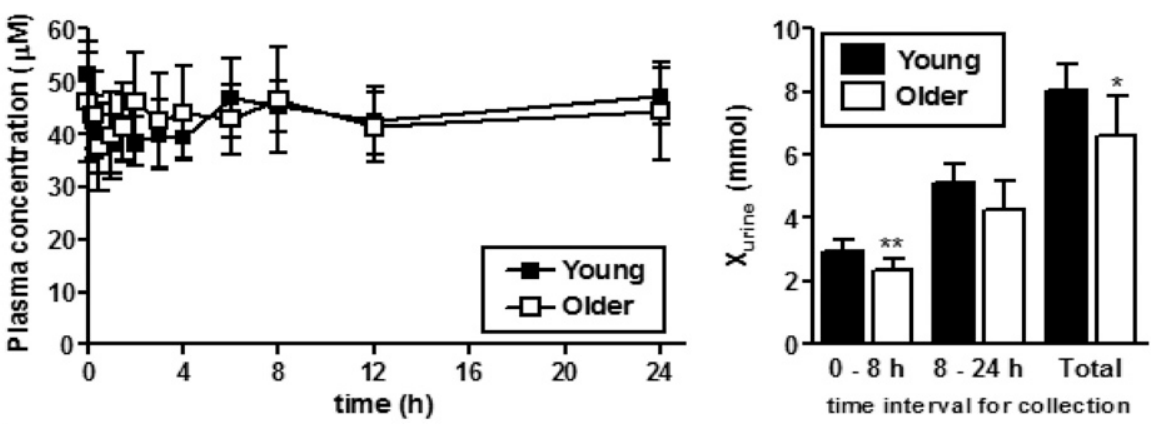

Fig. 7. Plasma concentrations and renal clearance of $\mathrm{m}^{\mathrm{A}} \mathrm{A}$ in younger and older volunteers. Plasma concentration profiles and urinary excretion of $\mathrm{m}^{1} \mathrm{~A}$ and creatinine (A) in younger and older volunteers (B) were determined. Each symbol and bar represents the mean \pm S.D. of eight and seven subjects. $* P<0.05$; $* * P<0.01 ; * * * P<0.001$, younger vs. older, Student's two-tailed unpaired $t$ test.

B
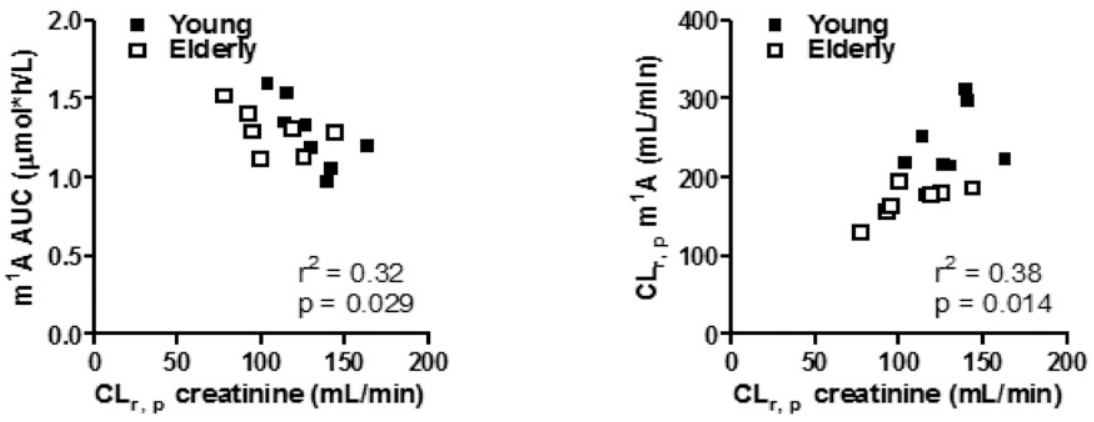

the luminal efflux. On the other hand, the kinetics of exogenously given $\mathrm{m}^{1} \mathrm{~A}$ was almost identical between WT and Mdr1a/1b/Abcg2 triple knockout mice (Supplemental Fig. 6; Supplemental Table 4), confirming the predominant role of mMate1 in the efflux of $\mathrm{m}^{1} \mathrm{~A}$ across the brush border membrane in mice.

Recently, cynomolgus monkeys have been used as a surrogate model to evaluate pharmacokinetic changes by the inhibition of renal drug transporters (Tahara et al., 2006; Shen et al., 2016). Monkey cation transporters exhibit a high similarity to their human counterparts, represented by amino acid sequence, transport properties such as substrate selectivity and $\mathrm{pH}$ dependency, and inhibition constants of various inhibitors (Shen et al., 2016). In accordance with these similarities, intravenous infusion of PYR caused the reduction of metformin renal clearance in cynomolgus monkeys (Shen et al., 2016), as is the case for oral PYR pretreatment in humans (Kusuhara et al., 2011). In our study, administration of DX-619, a potent OCT2 and MATE1/2-K inhibitor, resulted in an increase in $\mathrm{AUC}_{\mathrm{p}}$ of both $\mathrm{m}^{1} \mathrm{~A}$ and metformin (Fig. 6), indicating the potency of plasma $\mathrm{m}^{1} \mathrm{~A}$ concentration

TABLE 6

Pharmacokinetic parameters of $\mathrm{m}^{1} \mathrm{~A}$ in younger and older Japanese volunteers

Each value was determined from the data shown in Fig. 7. The equations to calculate the kinetic parameters are described in Materials and Methods. Each value represents the mean \pm S.D. of eight and seven subjects; Student's two-tailed unpaired $\mathrm{t}$ test; younger vs. older. Subject information is shown in Supplemental Table 4.

\begin{tabular}{|c|c|c|c|c|c|c|}
\hline \multirow{2}{*}{ Parameter } & \multicolumn{3}{|c|}{$\mathrm{m}^{1} \mathrm{~A}$} & \multicolumn{3}{|c|}{ Creatinine } \\
\hline & Younger & Older & Unit & Younger & Older & Unit \\
\hline $\mathrm{AUC}_{0-24 \mathrm{~h}}$ & $1.22 \pm 0.22$ & $1.29 \pm 0.14$ & $\mu \mathrm{mol}$ per $\mathrm{h} / \mathrm{l}$ & $1.05 \pm 0.12$ & $1.04 \pm 0.16$ & $\mathrm{mmol}$ per $\mathrm{h} / \mathrm{l}$ \\
\hline$X_{\text {urine, } 0-24 \mathrm{~h}}$ & $17.2 \pm 1.4$ & $13.0 \pm 0.9^{* * *}$ & $\mu \mathrm{mol}$ & $8.06 \pm 0.79$ & $6.61 \pm 1.17$ & mmol \\
\hline $\mathrm{CL}_{\mathrm{r}, \mathrm{p}}$ & $244 \pm 58$ & $169 \pm 22^{* *}$ & $\mathrm{ml} / \mathrm{min}$ & $129 \pm 18$ & $108 \pm 21$ & $\mathrm{ml} / \mathrm{min}$ \\
\hline
\end{tabular}

$\mathrm{AUC}_{0-24 \mathrm{~h}}$, area under the plasma concentration-time curve from 0 to 24 hours; $X_{\text {urine, } 0-24 \mathrm{~h}}$, amount excreted into the urine from 0 to 24 hours.

$P<0.01 ; * * * P<0.001$. 
as a biomarker for the evaluation of OCT2/MATE2-K-mediated DDIs. This is a salient feature not found in other endogenous substrates of OCT2/MATEs, such as NMN and creatinine. In practice, the plasma concentration is a better biomarker than renal clearance or urinary recovery, considering the simplicity of sample collection. The plasma creatinine concentration also exhibited an increasing tendency in the DX-619-treated period. Although metformin was eliminated from the systemic circulation at 24 hours after DX-619 administration, the plasma creatinine concentration remained high. Considering that in humans the serum elimination half-life of creatinine (3.85 hours) (Chiou and Hsu, 1975 ) is shorter than metformin (4.0-8.7 hours) (Dunn and Peters, 1995) there might be other mechanisms to alter the kinetics of creatinine- of course, further studies in cynomolgus monkeys are needed.

Finally, we investigated the time profiles of plasma concentration and urinary excretion of $\mathrm{m}^{1} \mathrm{~A}$ and creatinine in healthy younger and older volunteers (Fig. 7; Table 6). Like creatinine, the plasma concentrations of $\mathrm{m}^{1} \mathrm{~A}$ showed minimal diurnal variation for 24 hours. The renal clearance of $\mathrm{m}^{1} \mathrm{~A}$ was revealed to be approximately 2-fold higher than that of creatinine, indicating a greater contribution of the tubular secretion to the net urinary excretion of $\mathrm{m}^{1} \mathrm{~A}$. Correlation analysis suggested that the $\mathrm{m}^{1} \mathrm{~A}$ AUC and renal clearance reflected renal function, including OCT2/MATE2-K activity. The renal clearances of $\mathrm{m}^{1} \mathrm{~A}$ and creatinine were $31 \%$ and $17 \%$ lower in older volunteers than in younger volunteers, respectively. This is probably why the plasma $\mathrm{m}^{1} \mathrm{~A}$ concentrations were slightly higher in older volunteers, although this was not the case with creatinine.

The major challenge remaining is to examine the effect of OCT2/ MATE2-K inhibitors or genetic variants on $\mathrm{m}^{1} \mathrm{~A}$ kinetics in humans. It was previously reported that the serum $\mathrm{m}^{1} \mathrm{~A}$ level was significantly associated only with genetic variants of OCT2 in a metabolomic and genome-wide association study (Shin et al., 2014), whereas nonsynonymous single nucleotide polymorphism in the coding region was not included in those variants (Supplemental Table 5). In accordance with genome-wide association study, no effect of G808T mutation on hOCT2mediated $\mathrm{m}^{1} \mathrm{~A}$ uptake was observed in vitro (Supplemental Fig. 2). To conclude, the performance of $\mathrm{m}^{1} \mathrm{~A}$ as a surrogate probe of OCT2 and MATE2-K needs further clinical studies using their inhibitors.

In addition, the contribution of other transporters to the disposition of $\mathrm{m}^{1} \mathrm{~A}$ remains to be revealed. In our experiment, ENT-mediated $\mathrm{m}^{1} \mathrm{~A}$ uptake was observed in HEK293 parental cells (Supplemental Fig. 1A). Although ENTs did not appear to have major roles in the renal secretion of $\mathrm{m}^{1} \mathrm{~A}$ in mice, the effect of ENT inhibition on the systemic exposure of $\mathrm{m}^{1} \mathrm{~A}$ needs further investigation, considering the ubiquitous expression of ENTs (Young et al., 2013). The $\mathrm{m}^{1} \mathrm{~A}$ transport by organic anion transporters expressing in basolateral membrane of proximal tubular cells must also be checked, which we could not precisely evaluate using transporter-overexpressing HEK293 cells because of the inhibition of organic anion transporters by dipyridamole (data not shown).

In conclusion, we found $\mathrm{m}^{1} \mathrm{~A}$ was a novel endogenous substrate of OCT2 and MATE2-K. $\mathrm{m}^{1} \mathrm{~A}$ is a renal excretion-type compound that undergoes tubular secretion via those transporters in animals and humans. This study has provided the potency of $\mathrm{m}^{1} \mathrm{~A}$ as a biomarker for OCT2/MATE2-K in future clinical DDI studies.

\section{Authorship Contributions}

Participated in research design: Miyake, Mizuno, Ieiri, Maeda, Kusuhara. Conducted experiments: Miyake, Takehara, Mochizuki, Kimura, Matsuki, Irie, Watanabe, Ando.

Contributed new reagents or analytic tools: Kato.

Performed data analysis: Miyake, Takehara, Watanabe, Ando, Kusuhara.

Wrote or contributed to the writing of the manuscript: Miyake, Mizuno, Takehara, Ando, Kusuhara.

\section{References}

Arakawa H, Omote S, and Tamai I (2017) Inhibitory effect of crizotinib on creatinine uptake by renal secretory transporter OCT2. J Pharm Sci 106:2899-2903.

Breyer MD and Qi Z (2010) Better nephrology for mice—and man. Kidney Int 77:487-489.

Chen L, Shu Y, Liang X, Chen EC, Yee SW, Zur AA, Li S, Xu L, Keshari KR, Lin MJ, et al (2014) OCT1 is a high-capacity thiamine transporter that regulates hepatic steatosis and is a target of metformin. Proc Natl Acad Sci USA 111:9983-9988.

Chiou WL and Hsu FH (1975) Pharmacokinetics of creatinine in man and its implications in the monitoring of renal function and in dosage regimen modifications in patients with renal insufficiency. $J$ Clin Pharmacol 15:427-434.

Chu X, Liao M, Shen H, Yoshida K, Zur AA, Arya V, Galetin A, Giacomini KM, Hanna I, Kusuhara H, et al.; International Transporter Consortium (2018) Clinical probes and endogenous biomarkers as substrates for transporter drug-drug interaction evaluation: perspectives from the international transporter consortium. Clin Pharmacol Ther 104: 836-864.

Dunn CJ and Peters DH (1995) Metformin. A review of its pharmacological properties and therapeutic use in non-insulin-dependent diabetes mellitus. Drugs 49:721-749.

Dutta SP and Chheda GB (1987) Metabolism of 1-methyladenosine. Biochem Med Metab Biol 38:69-73.

Elsby R, Chidlaw S, Outteridge S, Pickering S, Radcliffe A, Sullivan R, Jones H, and Butler P (2017) Mechanistic in vitro studies confirm that inhibition of the renal apical efflux transporter multidrug and toxin extrusion (MATE) 1, and not altered absorption, underlies the increased metformin exposure observed in clinical interactions with cimetidine, trimethoprim or pyrimethamine. Pharmacol Res Perspect 5 :e00357.

Gessner A, König J, and Fromm MF (2018) Contribution of multidrug and toxin extrusion protein 1 (MATE1) to renal secretion of trimethylamine-N-oxide (TMAO). Sci Rep 8:6659.

Hacker K, Maas R, Kornhuber J, Fromm MF, and Zolk O (2015) Substrate-dependent inhibition of the human organic cation transporter OCT2: a comparison of metformin with experimental substrates. PLoS One 10:e0136451.

Imamura Y, Murayama N, Okudaira N, Kurihara A, Okazaki O, Izumi T, Inoue K, Yuasa H, Kusuhara H, and Sugiyama Y (2011) Prediction of fluoroquinolone-induced elevation in serum creatinine levels: a case of drug-endogenous substance interaction involving the inhibition of renal secretion. Clin Pharmacol Ther 89:81-88.

Ito S, Kusuhara H, Kumagai Y, Moriyama Y, Inoue K, Kondo T, Nakayama H, Horita S, Tanabe K, Yuasa H, et al. (2012) $N$-methylnicotinamide is an endogenous probe for evaluation of drug-drug interactions involving multidrug and toxin extrusions (MATE1 and MATE2-K). Clin Pharmacol Ther 92:635-641.

Ito S, Kusuhara H, Kuroiwa Y, Wu C, Moriyama Y, Inoue K, Kondo T, Yuasa H, Nakayama H, Horita S, et al. (2010) Potent and specific inhibition of mMate1-mediated efflux of type I organic cations in the liver and kidney by pyrimethamine. $J$ Pharmacol Exp Ther 333:341-350.

Johansson S, Read J, Oliver S, Steinberg M, Li Y, Lisbon E, Mathews D, Leese PT, and Martin P (2014) Pharmacokinetic evaluations of the co-administrations of vandetanib and metformin, digoxin, midazolam, omeprazole or ranitidine. Clin Pharmacokinet 53:837-847.

Jonker JW, Wagenaar E, Van Eijl S, and Schinkel AH (2003) Deficiency in the organic cation transporters 1 and 2 (Oct1/Oct2 [Slc22a1/Slc22a2]) in mice abolishes renal secretion of organic cations. Mol Cell Biol 23:7902-7908.

Kito T, Ito S, Mizuno T, Maeda K, and Kusuhara H (2019) Investigation of non-linear Mate1mediated efflux of trimethoprim in the mouse kidney as the mechanism underlying drug-drug interactions between trimethoprim and organic cations in the kidney. Drug Metab Pharmacokinet 34:87-94 Available from: 10.1016/J.DMPK.2018.08.005.

Kusuhara H, Ito S, Kumagai Y, Jiang M, Shiroshita T, Moriyama Y, Inoue K, Yuasa H, and Sugiyama Y (2011) Effects of a MATE protein inhibitor, pyrimethamine, on the renal elimination of metformin at oral microdose and at therapeutic dose in healthy subjects. Clin Pharmacol Ther 89:837-844.

Lechner C, Ishiguro N, Fukuhara A, Shimizu H, Ohtsu N, Takatani M, Nishiyama K, Washio I, Yamamura N, and Kusuhara H (2016) Impact of experimental conditions on the evaluation of interactions between multidrug and toxin extrusion proteins and candidate drugs. Drug Metab Dispos 44:1381-1389.

Mariappan TT, Shen H, and Marathe P (2017) Endogenous biomarkers to assess drug-drug interactions by drug transporters and enzymes. Curr Drug Metab 18:757-768.

Masuda S, Terada T, Yonezawa A, Tanihara Y, Kishimoto K, Katsura T, Ogawa O, and Inui K (2006) Identification and functional characterization of a new human kidney-specific $\mathrm{H}^{+}$/organic cation antiporter, kidney-specific multidrug and toxin extrusion 2. J Am Soc Nephrol 17:2127-2135.

Mathialagan S, Rodrigues AD, and Feng B (2017) Evaluation of renal transporter inhibition using creatinine as a substrate in vitro to assess the clinical risk of elevated serum creatinine. J Pharm Sci 106:2535-2541

Mishima E, Inoue C, Saigusa D, Inoue R, Ito K, Suzuki Y, Jinno D, Tsukui Y, Akamatsu Y, Araki $\mathrm{M}$, et al. (2014) Conformational change in transfer RNA is an early indicator of acute cellular damage. J Am Soc Nephrol 25:2316-2326.

Miyake T, Mizuno T, Mochizuki T, Kimura M, Matsuki S, Irie S, Ieiri I, Maeda K, and Kusuhara H (2017) Involvement of organic cation transporters in the kinetics of trimethylamine N-oxide. I Pharm Sci 106:2542-2550.

Morrissey KM, Stocker SL, Wittwer MB, Xu L, and Giacomini KM (2013) Renal transporters in drug development. Annu Rev Pharmacol Toxicol 53:503-529.

Otsuka M, Matsumoto T, Morimoto R, Arioka S, Omote H, and Moriyama Y (2005) A human transporter protein that mediates the final excretion step for toxic organic cations. Proc Natl Acad Sci USA 102:17923-17928.

Reese MJ, Savina PM, Generaux GT, Tracey H, Humphreys JE, Kanaoka E, Webster LO, Harmon KA, Clarke JD, and Polli JW (2013) In vitro investigations into the roles of drug transporters and metabolizing enzymes in the disposition and drug interactions of dolutegravir, a HIV integrase inhibitor. Drug Metab Dispos 41:353-361.

Rodrigues AD, Taskar KS, Kusuhara H, and Sugiyama Y (2018) Endogenous probes for drug transporters: balancing vision with reality. Clin Pharmacol Ther 103:434-448.

Shen H, Liu T, Jiang H, Titsch C, Taylor K, Kandoussi H, Qiu X, Chen C, Sukrutharaj S, Kuit K et al. (2016) Cynomolgus monkey as a clinically relevant model to study transport 
involving renal organic cation transporters: in vitro and in vivo evaluation. Drug Metab Dispos 44:238-249.

Shin S-Y, Fauman EB, Petersen A-K, Krumsiek J, Santos R, Huang J, Arnold M, Erte I, Forgetta V, Yang T-P, et al.; Multiple Tissue Human Expression Resource (MuTHER) Consortium (2014) An atlas of genetic influences on human blood metabolites. Nat Genet 46:543-550.

Tahara H, Kusuhara H, Chida M, Fuse E, and Sugiyama Y (2006) Is the monkey an appropriate animal model to examine drug-drug interactions involving renal clearance? Effect of probenecid on the renal elimination of $\mathrm{H}_{2}$ receptor antagonists. J Pharmacol Exp Ther 316:1187-1194.

Teft WA, Morse BL, Leake BF, Wilson A, Mansell SE, Hegele RA, Ho RH, and Kim RB (2017) Identification and characterization of trimethylamine- $N$-oxide uptake and efflux transporters. $M o$ Pharm 14:310-318.

Yamaoka K, Tanigawara Y, Nakagawa T, and Uno T (1981) A pharmacokinetic analysis program (multi) for microcomputer. J Pharmacobiodyn 4:879-885.
Yoon H, Cho H-Y, Yoo H-D, Kim S-M, and Lee Y-B (2013) Influences of organic cation transporter polymorphisms on the population pharmacokinetics of metformin in healthy subjects. AAPS J 15:571-580.

Young JD, Yao SYM, Baldwin JM, Cass CE, and Baldwin SA (2013) The human concentrative and equilibrative nucleoside transporter families, SLC28 and SLC29. Mol Aspects Med 34:529-547. Zolk O (2012) Disposition of metformin: variability due to polymorphisms of organic cation transporters. Ann Med 44:119-129.

Address correspondence to: Dr. Hiroyuki Kusuhara, Laboratory of Molecular Pharmacokinetics, Graduate School of Pharmaceutical Sciences, The University of Tokyo, 7-3-1, Hongo, Bunkyo-ku, Tokyo 113-0033, Japan. E-mail: kusuhara@ mol.f.u-tokyo.ac.jp 